\title{
Téoros
}

Revue de recherche en tourisme

\section{Les auberges de jeunesse}

\section{François Vidal}

Volume 8, numéro 2, juillet 1989

\section{Hébergement et tourisme}

URI : https://id.erudit.org/iderudit/1080325ar

DOI : https://doi.org/10.7202/1080325ar

Aller au sommaire du numéro

\section{Éditeur(s)}

Université du Québec à Montréal

\section{ISSN}

0712-8657 (imprimé)

1923-2705 (numérique)

Découvrir la revue

\section{Citer cet article}

Vidal, F. (1989). Les auberges de jeunesse. Téoros, 8(2), 30-31.

https://doi.org/10.7202/1080325ar d'utilisation que vous pouvez consulter en ligne.

https://apropos.erudit.org/fr/usagers/politique-dutilisation/ 


\section{Les auberges de jeunesse}

\section{Quelques jalons historiques}

Afin de situer le réscau actuel des Auberges de jeunesse, quelques considerations sur le développement du mouvement ajiste s'imposent.

L'origine du concept d'Auberge de jeunesse remonte à la fin du XIXe siecle alors qu'en Allemagne, Richard Schirmanin développe un type d'hébergement rudimentaire destine à favoriser auprès des jeunes čtudiants la découverte de la nature. Sont alors jetées les bases philosophiques du mouvement de I'ajisme (A.J.: Auberge de jeunesse): la découverte de la nature demeure à ce jour un thème central de la mission générale de la Fédération Internationale des Auberges de Jeunesse.

- Dabord européen, le phénomene devient rapidement intemational: la création de l'Association Canadienne de l'Ajisme remonte aux années '30 en Alberia, alors que Mary Barclay fonde la toute premiere auberge localisce, pour l'été... dans une tente.

- L'histoire de l'Association Canadienne, seule entité reconnue au niveau international, retrace l'bvolution d'un organisme essenticllement privé, sans but lucratif et dédié à offrir des services aux membres du mouvement. Ses activités au Québec sont alors sous la reponsabilite de la "région du Saint-Laurent", subdivision d"une corporation unique pour le Canadia.

\section{Une version différente de I'Au- berge jeunesse}

A la fin des années. '60, lạ société québécoise (ct nord-américaine) vit degrands bouleversements: aux beatniks des années ' 50 ont succedé les "hippies" qui, dans lacontestation des valeurs de l'establishment, nthesitent pas à prendre la route, le plus souvent avec des moyens de fortune, a la recherehe d'une nouvelle identité. Des millier: de jeunes envahissent chaque eté les parcs des grands centres urbains. Les plus audacieux iront a Vancouver (l'équivalent canadien du California Dreaming!) alors que, plus pres de nous, les Iles-de-la-Madeleine deviendront une destination "mythique" des québécois.

Sous la pression des autorités municipales, le Secrétariat d'État du Gouvemement fédéral met alors sur pied un programme d"assistance financière à la crétion d'un réseau d'auberges de jeunesse en affectant à cette fin des fonds consulcrés à la création d'emplois temporaires.

Mais l'État québécois investissait simultanément ce champ d'activiles, développant d'abord en Gaspésie son propre réseau d'auberges. Ainsi, pendant 10 ans, trois réseaux distinets se partageront le territoire québecois:

= les auberges "provinciales" situées surtout en Gaspésic, â Québec et jusqu'en Abitibi,

- les auberges "fédérales" à Montréal, en Estrie, sur la Côte Nord et au Lac Saint-Jean;

- les auberges de I'Association Canadienne d"abord à Québec et à Montréal, avant de se limiter a celte seule ville.

\section{Croissance et déclin}

La decennie "70 voit done fleurir le phenomenes près de 40 auberges opèrent simultanément chaque été, une demi-douzaine passant à une opération annuelle. Toute cette effervescence ne sera pourtant que de courte duré, tant au niveau fédéral que provincial, l'État questionne la pertinence de son intervention. DLs 1978. Ie Quebec, constatant que la croissance du chiffre d'affaires des auberges subventionnes n'est attribuable qu'aux hausses de subventions, annonce quelques mesures administratives visunt a augmenter le dynamisme des auberges vers un meilleur autofinancement au cours des trois prochaines annes. En 1979, le programme fédéral des auberges est aboli sans autres formalités. Deux ans plus tard, on parle à Québec du retrait de l'intervention de l'État. Fin de la décennie 80 , le programme ne dispose plus que $\mathrm{du}$ quart des sommes qui lui étaient alloubes à chaque annee.

\section{L'ère de la survivance}

Une quinzaine d'auberges ont ouvert leurs portes â l'été 1989. Poursuivant dans l'ensemble la mêtne mission d'accueil des jeunes voyageurs dans une perspective de tourisme social, elles sont ă l'image des organisations qui les opèrent; caracteristique unique au Canada, le Québec ne compte à ce jour que sur des corporations indépendantes pour assurer la composition de son réseat. L'intervention limitee de l'Élat force desonmais les pourvoyeurs de services a repenser Icur action en fonction des règles d'un marché livre à la libre concurrence. Les notions de rentabilité, de marketing et d'autofinancement 
ont trouvé place dans le discours des auberges aux cotés de l'animation et de l'atmosphêre de rencontres. Il s'agit là d'ajustements dictés non seulement par les bouleversements administratifs mais surtout par les besoins des nouvelles gênêrations d'usagers.

C'est quion ne retrouve plus depuis plusicurs années (et malgré la perception populaire) qu'une minorité d"'ex-hippies sans-le-sou" dans le auberges. L'attrait de tarifs réduits n'est plus le principal facteur justifiant le choix d'une auberge de jeunesse. La clientèle moyenne valorise plus quavant l'intimité, le confort, la sécurité, la propreté, la localisation et la qualité des services offerts. En contrepartie, elle consent a des tarifs plus cleves, se comportant essentiellement comme liensemble des touristes moyens mais selon des séjours plus longs.

Dans les grands centres et quelques autres villes. le nombre d'européens dépasse depuis trois ans lè nombre de québécois. Sont apparus de façon plus significative des voyageurs d'Australie et de Nouvelle-Zélande: pour l'ensemble du Canada, leur nombre dépasse celui des voyageurs de France et d'Angleterre. Les moyennes d'äges varient peu, se situant autour de 23 ans. Mais ces données marquent une ré́alité plus complexe; on voit depuis quelques années des groupes d'élèves de niveau elémentaire ( 9 ans!) cotoyer des inconditionnels des auberges (dans la trentaine!). Comme dans le reste de l'industric, l'hébergement jeunesse se met à l'heure de la segmentation de marches.

Et pourtant lobservateur attentif ne peut manquer de déceler les signes d'un certain épuisement du réseau. A commencer par un problème de relève tant au niveau des conseils d'administration que du personnel et des usagers des auberges. Pour un réseau "jeunesse", le paradoxe atteint des dimensions critiques.

Si, sous l'impulsion de corporations mieux structurées, les ćtablissements des grands centres urbains ont vu leur fréquentation croitre au cours des cinq dernières années, l'ensemble des auberges du Québec accuse un plafonnement d'achalandage qui révèle le déclin des plus petites unités du réseau. Plusicurs régions du Québec n'ont plus d'auberge, et l'avenir de l'hébergement jeunesse en régions est chaque jour compromis.

\section{La relance}

Cest pourtant de la concertation quapparaît lémergence d'un nouveau concept de réseau pour les années '90. La Fédération Québécoise de l'Ajisme, hêritière de l'ancienne "région du Saint-Laurent" et regroupant toujours les détenteurs de la carte internationale de l'ajisme complète cet automne une fusion avec l'Organisation du Tourisme Étudiant du Québec (qui re- groupe une cinquantaine de bureaux-voyages dans les CÉGEPS et universités). Le Regroupement Tourisme Jeunesse ainsi forme entend se doter d'un plan de développenent stratégique du réseau des auberges au Québec. Issu des préoccupations d'une nouvelle génération de gestionnaires déterminés à en finir avec les cloisonnements, le R.T.J. présente, avec son affiliation intemationale et son approche systématique d'ensemble, les meilleures chances de développement pour les auberges au Québec. Au-dela des luttes de pouvoir autour du contrôle du réseau, cest l'avenir du Tourisme Jeunesse au Québec qui se joue aujourd'hui. Ses chances de succes n'ont jamais été aussi bonnes. 